\title{
Article
}

\section{Culture change in a professional sports team: Shaping environmental contexts and regulating power}

Cruickshank, A., Collins, D., and Minten, S.

Available at http://clok.uclan.ac.uk/8640/

Cruickshank, A. ORCID: 0000-0002-8893-2341, Collins, D., ORCID: 0000-00027601-0454 and Minten, S. (2013) Culture change in a professional sports team: Shaping environmental contexts and regulating power. International Journal of Sports Science and Coaching, 8 (2). pp. 271-290. ISSN 1747-9541

It is advisable to refer to the publisher's version if you intend to cite from the work. http://dx.doi.org/10.1260/1747-9541.8.2.271

For more information about UCLan's research in this area go to http://www.uclan.ac.uk/researchgroups/ and search for <name of research Group>.

For information about Research generally at UCLan please go to http://www.uclan.ac.uk/research/

All outputs in CLoK are protected by Intellectual Property Rights law, including Copyright law. Copyright, IPR and Moral Rights for the works on this site are retained by the individual authors and/or other copyright owners. Terms and conditions for use of this material are defined in the policies page.

\section{CLoK}

Central Lancashire online Knowledge www.clok.uclan.ac.uk

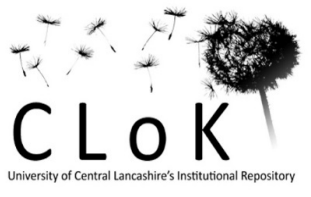




\title{
Culture Change in a Professional Sports Team: Shaping Environmental Contexts and Regulating Power
}

Andrew Cruickshank ${ }^{1}$, Dave Collins ${ }^{1,2}$ and Sue Minten ${ }^{3}$

${ }^{1}$ Institute of Coaching and Performance, School of Sport, Tourism and the

Outdoors, University of Central Lancashire, Preston, PR1 2HE, UK

E-mail: ACruickshank@uclan.ac.uk; DJCollins@uclan.ac.uk

${ }^{2}$ Grey Matters Performance Ltd, 181 Church Bank, Lower Binton, England, CV37 9TQ

E-mail: Dave@GM4P.com

${ }^{3}$ School of Sport, Tourism and the Outdoors, University of Central Lancashire, UK

E-mail: SMinten@uclan.ac.uk

\begin{abstract}
Although high performing cultures are crucial for the enduring success of professional sport performance teams, theoretical and practical understanding of how they are established and sustained is lacking. To develop knowledge in this area, a case study was undertaken to examine the key mechanisms and processes of a successful culture change programme at English Rugby Union's Leeds Carnegie. Exploring the change process from a 360 degree perspective, semi-structured interviews were conducted with team management, one specialist coach, six players, and the CEO. Analysed and explained through decentred theory, results revealed that culture change was effectively facilitated by team management: a) subtly and covertly shaping the physical, structural, and psychosocial context in which support staff and players made performance-impacting choices, and b) regulating the 'to and fro' of power which characterises professional sport performance teams. Decentred theory is also supported as an effective framework for culture change study.
\end{abstract}

Key words: Culture Change, Decentred Theory, High-Performance Sport, Rugby Union, Situated Agency

\section{INTRODUCTION}

While high performing cultures are central to the sustained success of professional sport performance teams, sport psychology currently offers limited understanding on how they can be actualised [1, 2]. Acknowledging the pan-continent 'sacking pandemic', whereby professional team managers are regularly fired for failing to deliver consistent results in short order [3-5], this knowledge gap in culture change delivery is a notable constraint in the 
optimisation of team performance and managerial longevity. Indeed, as formal conceptualisation of elite team culture change has only recently arrived, present guidance on this change management process is almost only available from business fields [cf. 2, 6]. Due to major methodological limitations within this latter line of enquiry alongside the hazards of applying business-based culture change solution to sports team performance settings [6], initial literature has therefore identified the need for domain-specific study into the processes and mechanisms of successful professional team culture change [2].

While the creation of optimal cultures has long been an implicit goal of professional team managers ${ }^{1}$ [7], culture change has only emerged as an explicit construct in applied literature of late $[1,7,8]$. Helping lay foundations for the conceptual and practical development of elite team culture change, Cruickshank and Collins [2] recently applied contemporary theorising in sport psychology, social psychology, and organisational studies to define team culture as "a dynamic process characterised by the shared values, beliefs, expectations and practices across the members and generations of a defined group" [p. 340]. Using this definition as a theoretical basis, the same authors subsequently conceptualised elite team culture change as the management-led establishment of shared and group-regulated values, perceptions, and behaviours across the performance department which persist over time and facilitate enduring high performance [2]. As a tangible applied activity, culture change is also: context-dependent (i.e., dependent upon performers and support staffs' agreement and/or accordance with change); context-shaped (i.e., shaped by the needs and opinions of high ego/status performers, diverse support staff, outcome-occupied Board, emotionallyattached fans, and sensationalising media); and context-specific (i.e., specific to the unfolding scenarios of manager takeover at a team with bespoke history, traditions, resources, and stakeholder expectations). Beyond illuminating the precise focus, nature, and scope of elite team culture change (i.e., what the construct is), initial work has also simultaneously revealed the limits of pre-existing knowledge in comprehensively accounting for the process (i.e., what the construct is not) [2].

Although sport psychology's interest in group dynamics has led to a broad understanding of the process markers or concomitants of high performance, such as goal setting [9] and role clarity [10], the worth of these factors for delivering professional team culture change are restricted. Most work to date has examined these processes' utility in non-elite/cross-team samples, correlation with outcomes, value in isolation (i.e., not in packaged programmes), and overlooked their efficacy and evolution during manager changeover [e.g., 9, 10]. More fundamentally, no research has focused on the generation of shared team knowledge at the individual beliefs level [2]. While understanding in group dynamics can direct practitioners to what a high performing culture might look like, it therefore offers limited advice on how managers can negotiate the varied, contested, and conflicting perceptions which characterise professional performance teams and ensure that processes are accepted, internalised, and governed by its members (n.b., intervention which fails to deliver these latter results is temporarily imposing, not changing culture) [2]. Since leadership is considered to shape member perception and behaviour [11], some may assert that such knowledge does already exist. However, leadership work has so far not extensively considered the: a) selection, deployment, and evolution of behaviour in specific contexts; b) systems, processes, and mechanisms which professional team managers should deliver; and c) extent to which the action and reaction of performers, support staff, and external stakeholders (e.g., CEOs)

\footnotetext{
${ }^{1}$ Manager/management are terms used as general labels to describe any individual responsible for the performance department of an elite sports team (i.e., the department encompassing team management, support staff, and performers)
} 
impacts on present and future decision making [cf., 2]. Beyond providing a partial picture of team functioning, recent work has also identified that current popular theories, such as transformational leadership [12], do not fully account for the behavioural repertoire of elite team managers; as evidenced, for example, by the prevalence and need for dark traits $[1,13]$.

Reflecting its standing in contemporary elite-team enquiry, it is also important to highlight professional team culture change's links with and demarcation from organisational sport psychology [14]. Regarding areas of overlap, optimal cultures have been increasingly implicated in effective organisational functioning and the relevance of culture change expertise suggested [e.g., 1, 15, 16]. For example, in examining a key member of national sport organisations, namely the Olympic performance director, Fletcher and Arnold [1] found that the "creation of a culture" was a principle feature of these figures' best practice. As this particular study focused on general performance director competencies, however, implications for the specific study and practice of culture change are limited. Furthermore, with other work in this field adopting a more holistic approach to organisational functioning (including examination of chief executive officers, administrators, volunteers, and committee members) $[16,17]$ and not primarily focused on culture change delivery, it is difficult to extrapolate lessons for performance team-specific culture change processes. However, even if culture change does establish itself on the organisational sport psychology agenda, which seems likely and valuable [15], ensuing knowledge would arguably provide diluted implications for the process as it prevails in elite team performance departments.

Similar to the inherent issues of uncritically applying business-based change management frameworks [6], organisational sport psychology's pursuit of holistic, organisation-wide (rather than focused, role/department-specific) knowledge will likely curtail its ability to provide culture change lessons which are optimally sensitive to the unique contexts of the elite sport performance department. To clarify, with organisational sport psychology generating knowledge at a higher level of social aggregation (i.e., the whole organisation) than performance team culture change (i.e., part of an organisation) [14], the intended broad scope of organisation-level study compromises its ability to best understand and explain the finer details which underpin and shape department-specific processes (just as both organisational- and team culture-focused work are limited in their ability to understand and explain individual performer-level processes). In short, as culture change is dependent on, shaped by, and specific to the context in which it is delivered, knowledge emanating from organisational sport psychology will therefore be potentially useful but inevitably not optimal due to key differences between elite sport performance team and business environments. For example, the motivations, needs, and preferences of professional sports team performers - particularly those in higher profile sports - vary considerably from those involved in administrative departments; as shaped by the complimentary yet distinct goals of organisational and performance departments (i.e., sports business/administrative- versus sports performance-focused) [18] and professional sports team performers' high ego orientation, inflated salaries, and media eminence $[2,6]$.

Extending upon these points, while management structures in both organisational and performance departments may mirror autocratic, hierarchical models [18], professional sport performance departments are unique in their nature and distribution of power. For example, unlike normal business employees, professional sports team performers are often paid more than their 'superiors' [6], are responsible for 'product' delivery (i.e., performance) in a wide public setting, and are subject to major attention from key external stakeholders (e.g., fans, media). Reflecting the extent of professional team performers' programme-shaping power [19], the success and survival of the performance team manager is arguably, therefore, more 
intricately governed by the beliefs, decisions, and actions of those they are employed to lead than their management equivalents in more top-down organisational departments. We do not suggest here that business leaders are less dependent on their subordinates than professional sports team managers; rather the unique nature and flow of power within a professional sport performance team renders its 'leader-follower' relationships inherently different.

Recognising that professional team culture change is therefore an important and unique construct, what type of approach is required to study its delivery? Firstly, and aligning with our earlier points on leadership, if the practitioner's intention is to facilitate culture change then leader-centric approaches are conceptually unsuitable. While previous enquiry into success culture creation has centred on the leader's perspective [7, 8], enduring cultural change requires people to change. When Schroeder [8] interviewed NCAA-level programme leaders, the omission of key internal (i.e., athletes, support staff) and external (i.e. board members) stakeholders was therefore a particular limitation. Precisely, this 'data gap' inhibited a broad understanding of the extent to which change-processes and mechanisms were uniformly perceived, considered impactful, and, perhaps most significantly, whether they were at the root of performance improvement. For sport psychology to develop sound culture change theory and practice there is a need to embrace social complexity and explore from a 360 degree perspective.

While assessing multiple perspectives may optimise the accuracy of interpretation, it is equally vital that perceptions depict culture change as it prevails in professional sport performance departments. Although Schroeder [8] used Schein's [20] organisational model to guide culture change enquiry, and organisational sport psychology has adopted businessbased knowledge to inform work on elite sport organisation functioning [e.g., 16], a recent review suggests that uncritically and directly applying understanding from business for professional team culture change study is hazardous. Specifically, while business has devoted notable resource into elucidating the delivery of pan-individual change, Cruickshank and Collins [6] have discussed in detail how knowledge transfer from this area is hamstrung by: a) numerous and substantial methodological flaws, and, as detailed above, (b) the subtle yet vital contextual and power-based differences between professional sport performance departments and businesses. It is therefore crucial that early exploration of professional team culture change facilitates understanding which is sensitive to the setting's unique features; in particular its characteristic 'power flux' (e.g., the power struggle between management, staff, and performers described above).

As well as acquiring multiple and accurate perceptions, it is also key that professional team culture change work is explained via appropriate theoretical frameworks. Recently embraced by sport policy research [21-23] and further identified by sport psychology as a possible interpretive tool for performance team culture change $[2,6]$, decentred theory may represent one such approach [24]. Originating from work into the UK's shift from central governmental power in policy creation and delivery to governance through distributed networks, decentred theory was developed as an anti-foundational alternative to previously positivist-dominated literature on this topic $[24,25]$. Specifically, based on the assumption that governance arises dynamically via bottom-up processes as opposed to linearly via institutional or structural imposition, decentred theory sought to reinstate individuals to the "agentless" portrayals which had come before [21, p. 161]. As such, and countering prior accounts from foundational-based epistemologies, the decentred perspective conceptualises network members not as passive actors but instead as divergent situated agents: i.e., individuals who reason and act in a novel manner within the contexts in which they operate [24]. By rejecting top-down and uncontested approaches to change, social reform is 
therefore depicted as a "chaotic picture of multiple actors, creating a contingent pattern of rule through their conflicting actions" [24, p. 7].

On evaluating decentred theory's underpinning features, a close match is found with the contexts and needs of elite team culture change research. Developmentally, decentred theory's move to uncover how governance networks (i.e., parallel of high performing cultures) are constructed rather than their traits and outcomes (i.e., parallel of sport psychology's group dynamics work) or their links with central direction (i.e., parallel of sport psychology's leadership work) [24] mirrors the evolution of the elite team culture change construct. Conceptually, with such networks usually "[operating] through interdependent relationships, with a view to trying to secure their individual goals by collaborating with each other" $[24$, p. 3], similarity is found with the variously-motivated, multi-group make up of professional sport performance departments. Reflecting their pursuit of bespoke goals and possession of role- and person-specific needs, preferences, and opinions, the elite sport performance team's management, support staff, and performers can also therefore be viewed as situated agents. Notably, the "radical contingency" [21, p. 161] assumed to emerge from the interplay of these agents' diverse and conflicting beliefs aligns with recent literature on the personal, power-ridden, and contested nature of leading sports teams [26]. Finally, although sport policy researchers have argued for a modified decentred approach to best explain sports governance issues (accounting for the role of institutions and structures as well as individual beliefs and practices) [21, 22], initial work in this field has nonetheless reinforced decentred theory's possible utility for sport psychology matters by pointing to the perspective's ability to illuminate social complexity, diverse interests, and multi-stakeholder agency [23].

While sport policy research has positioned decentred theory within an interpretivist or 'hard' interpretivist epistemology [21-23], Bevir and Richards [24, p. 3] consistently assert that "to decentre is to focus on the social construction of a practice [emphasis added]". Noting that "researchers may use similar methods but from very different epistemological perspectives" [27, p. 89], it is the social constructionist position which appears most appropriate for explaining performance team culture change. With social constructionism viewing culture change as "highly political processes of power, which result in the elevation of specific forms of knowledge to the rank of the true ... for a specific context [emphasis added]" [28, p. 279], such an epistemology aligns with performance departments' contextand power-governed features (as described above). Applying these philosophical foundations, decentred theory consequently points to the saliency of unearthing changeprocesses and mechanisms via methods which: a) "do not pre-empt or curtail the richness and contingency of findings" [29, p. 39], b) consider a range of agents beyond those who dominate through structural position [23], and c) focus on how networks (e.g., performance departments) construct and reconstruct new ways of perceiving and behaving [24]. Via its prioritisation of context, multiple stakeholder focus, and sensitivity to the dynamic and contested nature of social processes, decentred theory may therefore offer an effective account of professional team culture change.

Recognising the importance of culture change expertise for optimising professional sport team performance and manager longevity, alongside the need to unearth theoretical approaches through which the process may be understood, the purpose of the present study was to explore culture change from a decentred perspective. To advance practical and theoretical understanding, the study had three objectives: a) to uncover key mechanisms of culture change as perceived by multiple stakeholders; b) to elucidate systems, processes, and procedures which manage and exploit the inherent power flux in professional sport 
performance teams; and c) to operationalise and assess the utility of decentred theory as a framework for enquiry. To meet these intentions, a case study of a recently successful culture change programme was selected.

\section{METHOD}

Considering its ability to proliferate "multiple maps of the world as it is experienced" [30, p. 344], qualitative methodology was considered appropriate for enquiry. The suitability of case study methodology was also supported by its prior deployment in other work using decentred theory as an explanatory framework [23]. Applying the terminology of Stake [31], the present study was instrumental in nature in that it sought to provide a contextually-bound account of the case and wider insight into professional team culture change. Adhering to the responsibilities of case study researchers [31], patterns of data were used to develop issues, individual perceptions triangulated with others, and alternative explanations evaluated (cf. trustworthiness section). To meet presentational criteria, research questions have been emphasised (cf., study purpose), the boundaries of the case set (cf., immediate proceeding section) and assertions developed about the case (cf., results and general discussion).

SELECTION OF AN EXEMPLAR CULTURE CHANGE PROGRAMME: LEEDS CARNEGIE 2008-2010

Following the professionalisation of Rugby Football Union in 1995, Leeds Carnegie (formerly Leeds Tykes and Leeds RUFC) were named champions of English Rugby Union's second tier professional league (now named The RFU Championship) for the first time in season 2000-2001 and consequently promoted (i.e., permitted entry) to the governing body's top division (now named the Aviva Premiership) for season 2001-2002. However, despite finishing fifth in their maiden season (therefore qualifying for the world's most prestigious club tournament, the Heineken Cup) and winning their first ever trophy in 2004-2005, the Club was relegated (i.e., demoted) back to the second tier at the end of 2005-2006 (as a result of finishing last in the Premiership standings) before consecutive promotion and relegation in 2006-2007 and 2007-2008. Upon the Director of Rugby's departure at the end of this latter campaign, the Club appointed Andy Key and Neil Back (hereafter AK and NB) as Director of Rugby and Head Coach respectively. Arriving from Leicester Tigers, English rugby's most successful club, the team was promoted at the end of the management's first season before finishing tenth out of the Premiership's 12 teams in 2009-2010, thereby maintaining their status in the league and breaking the previous promotion-relegation cycle (for which AK received the Premiership's Director of the Year award). The Club was selected for the present study based upon AK and NB's confirmation that their programme focused explicitly on culture optimisation and that successful performance had been: a) recently experienced, and b) delivered in the face of notable contextual challenges (i.e., history of successive promotion-relegation; significantly increased level of competition).

\section{PARTICIPANTS}

A sample critically implicated in professional team culture change was recruited [2]. Beyond enlisting $\mathrm{AK}$ and $\mathrm{NB}$, one member of support staff (a specialist coach) and six first team squad players were recruited. As a further means for assessing the change process, two players were at the Club before AK and NB's appointment, two were recruited in the 2009 off-season, and two recruited in the 2010 off-season. Additionally, reflecting the reported need to 'manage upwards', with respect to gaining the time, space, and resources from toplevel management to facilitate optimal programme delivery [2, 6], the Chief Executive 
Officer (CEO), Gary Hetherington, was also recruited. The specialist coach and CEO were both employed by the Club before AK and NB's arrival.

\section{DESIGN}

A semi-structured interview guide of open-ended questions was created to obtain a broad and in-depth understanding of each participant's perceptions. To encourage specific detail, follow-up probes were prepared. Both guide and probes were piloted with three head coaches and critically evaluated using procedures identified by Patton [32].

\section{PROCEDURE}

All participants were approached on behalf of the authors by AK and NB to gauge interest in taking part in the study. Upon confirmatory response (all accepted), individual letters were sent providing further information on the work and commitments of participation. To encourage critical evaluation by the players and specialist coach, particular emphasis was placed upon the confidential nature of their contribution and direct reassurance by management that the Club would not be permitted access to any of the recorded information. As naming the Club meant that there was no feasible way to conceal the identities of AK, $\mathrm{NB}$, and the CEO, these participants were made explicitly aware that they would be accountable for their provided information. All participants subsequently provided informed consent, with $\mathrm{AK}, \mathrm{NB}$, and the $\mathrm{CEO}$ agreeing to be named in the paper and all players agreeing to the description provided above.

Representing their joint responsibility for delivering change, AK and NB were interviewed simultaneously and first. Reflecting the retrospective nature of enquiry, they were initially requested to plot a timeline of the team's perceived performance against that required of a top-four Premiership side (the management team's programme goal). It was further requested that the emergent graph be split into phases representing distinct periods in the change process as demarcated by major and chronological events [cf., 33]. This depiction was then employed as both an aid to recall and tool to frame interview questions for all participants (i.e., questions were asked in relation to the initial changes, transition between phases, and in-phase events). Cognisant of the intention to obtain data grounded in individual experience, however, other participants were initially asked to share their views on the timeline and provided opportunity to amend AK and NB's depiction to best represent their own beliefs, thereby tailoring their reference of questioning. Similarly, while a semistructured guide was utilised, the interview was based upon a 'talk me through it' conversational approach and shaped by the content and natural flow of each discussion [32]. After covering all identified phases, final questions were asked relating to the holistic process, nature and outcomes of the change.

All interviews were audio recorded and conducted by the first author in a private office at the Club's training ground, apart from that with the CEO which took place in a private room at the Club's stadium. To inhibit current contextual factors interacting with retrospective perception and individuals discussing their interview with those still to participate, all interviews were conducted over 1 week (players over 3 consecutive days). Interviews with the players ranged from approximately 60 to 150 minutes, as governed by their length of service. The interview with the management lasted 250 minutes, specialist coach 300 minutes, and CEO 135 minutes. The shorter length of the CEO's interview reflected this figure's diluted picture of the culture change process, as dictated by their 'distance' from the performance department (see supporting comments below). All procedures were approved by the authors' institutional ethics committee. 
INDUCTIVE ANALYSIS OF STAKEHOLDER PERCEPTIONS

Aligning with previous decentred study [cf., 23, 34], inductive content analyses were conducted on each participant's data. After reading and rereading the transcription, qualitative analysis software (QSR NVIVO 9) was used to transform raw data units into thematic hierarchies by recursively engaging in tag creation, category creation, and category organisation [35]. To revise identified concepts based upon emerging analysis, the constant comparative method was employed and conceptual memos recorded detailing evolving ideas and key notes [36]. Reflecting the focus on team culture, all analysed players' interviews were then amalgamated to produce a set of perceptions indicative of the group as a whole.

\section{ADDRESSING TRUSTWORTHINESS}

Several approaches were employed to optimise trust and rapport with interviewees (later corroborated by AK and NB). These included: a) prior investigation of all participants' careers to understand their bespoke history and current situation (n.b., the first author had no pre-existing relationship with any participant prior to the research); b) observation of two training sessions, the training complex, office environment, and a meeting delivered by AK and NB to Club coaches; and c) knowledge of and empathy with the demands of professional team and culture change environments (as facilitated by the first author's prior experience as a professional soccer player and recipient of new managers' programmes). Member checks were also conducted, involving a 10-15 minute meeting with each participant to discuss emerging results and the accuracy and fairness of quotes considered for inclusion in the paper from that individual. Importantly, feedback was sought on the researchers' interpretation of these quotes and the context of the results subsection in which they appeared. No thematic categories were changed from this feedback process and 2 of 34 exemplar quotes were slightly adjusted. Reflecting their responsibility for programme delivery, AK and NB were then provided with a full copy of the results to comment on the paper's overall precision. Both reported complete agreement with its depiction.

Trustworthiness of the analytical process was also addressed. Facilitated by QSR NVIVO's optimisation of transparency, the constant comparison method and conceptual memos challenging interpretation ensured that evolving meaning was continually reevaluated and reasserted [cf., 36]. To further optimise rigour, a reflexive journal was maintained [32]. Additionally, the third author (an experienced qualitative researcher) read four transcripts (AK/NB, CEO, specialist coach, longest serving player) and assessed a priori interpretations of meaning units against the labels created by the first author and their fit with the overall thematic structure. In the few cases of alternative explanation and queries over accuracy, reflective discussion took place until all themes and their location in the thematic hierarchy were agreed [31]. Promoting the first and third authors' cognisance of their presumptions and assumptions, the second author acted as a 'critical friend' by supporting indepth critique and investigation of emerging interpretation, discoveries, and explanations [37].

\section{RECENTRED ANALYSIS OF HIGHER ORDER THEMES}

Once decentred accounts are obtained, an understanding of broader narratives, such as the culture change process, may then be achieved by providing a "recentred" [38, p. 139] account. By assessing the coherency of higher order themes across all groups (i.e., management, specialist coach, players, CEO), a triangulated, meso-level generalisation of the change-facilitating mechanisms and processes was therefore obtained. Importantly, such accounts are required to maintain a description of "contingent patterns of action in their specific contexts" and consider power "as something that flows up and down" [38, p. 139]. 
The results consequently present and discuss the commonality of perceived performance and action, discrepancy in perceived performance and action, change mechanisms, and powersensitive processes with these qualifications in mind.

\section{RESULTS}

VALIDATING THE CULTURE CHANGE: THE COHERENCE OF PERCEIVED PERFORMANCE AND ACTION

Reflecting objectives to unearth the mechanisms and power-sensitive processes of professional team culture change, we firstly clarify programme success to confirm the validity of results and their implications. Beyond enhanced performance (cf., method section), programme effectiveness was verified by process and perception markers [cf., 6]. Regarding the former, inherent within the results are a number of processes introduced or optimised to facilitate high performance (e.g., role clarity, performance feedback). However, viewing culture as a primarily social construction, evidence of programme utility is more notably provided in the perceptions detailed in Figure 1 and Table 1, which show high levels

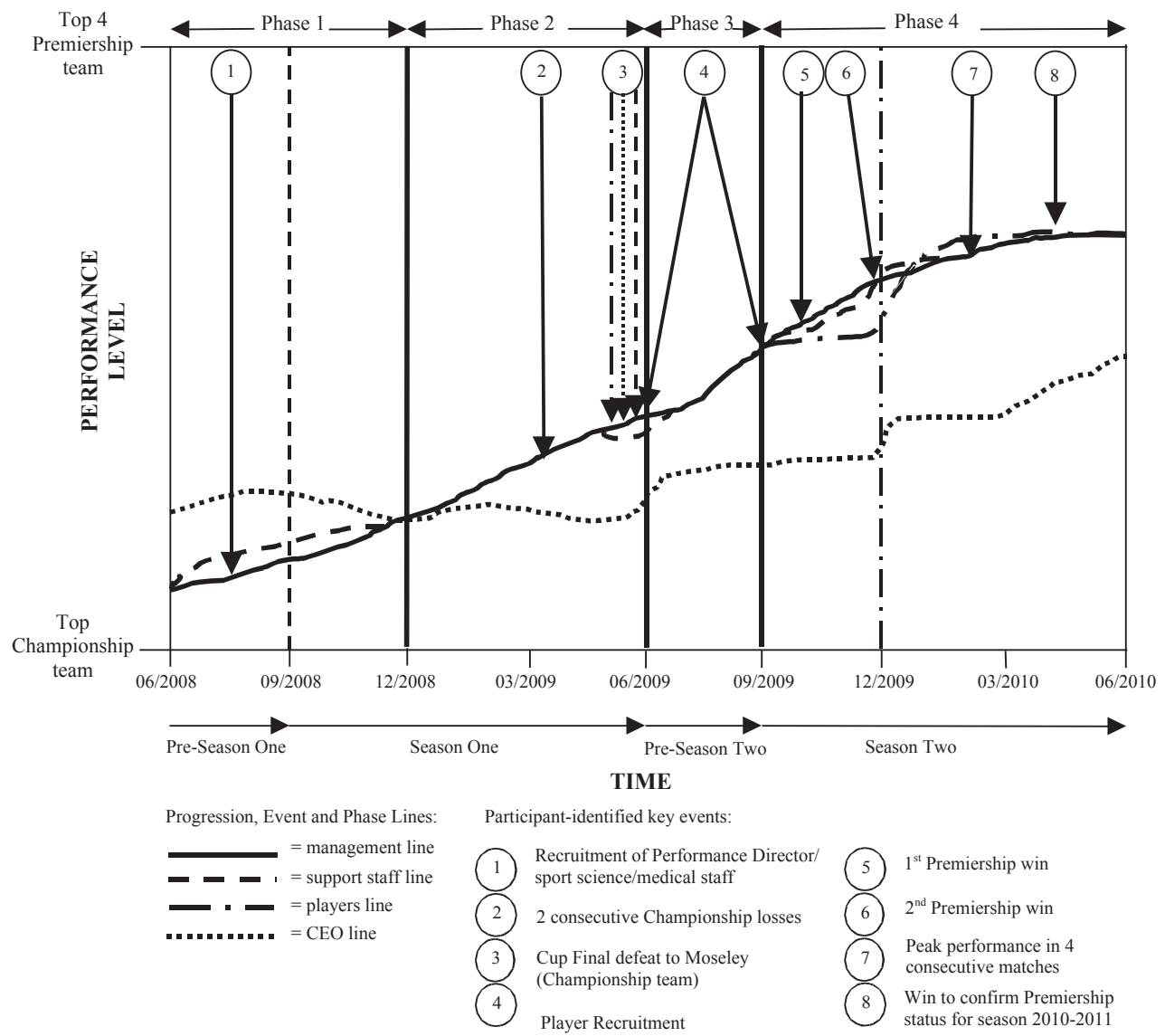

Figure 1. Team Performance Level, Key Events and Distinct Phases of the Change Process as Perceived by Each Participant Group

Phases displayed at the top of the figure represent those perceived by the management. Where no lines belonging to the players, support staff and CEO are present, this reflects agreement with the management's perceptions. Lines belonging specifically to the players offer a 'best fit' representation of the group's perceptions as a whole. 
Table 1. Higher-Order Constructs of the Culture Change Program

$\underline{\text { Category }}$

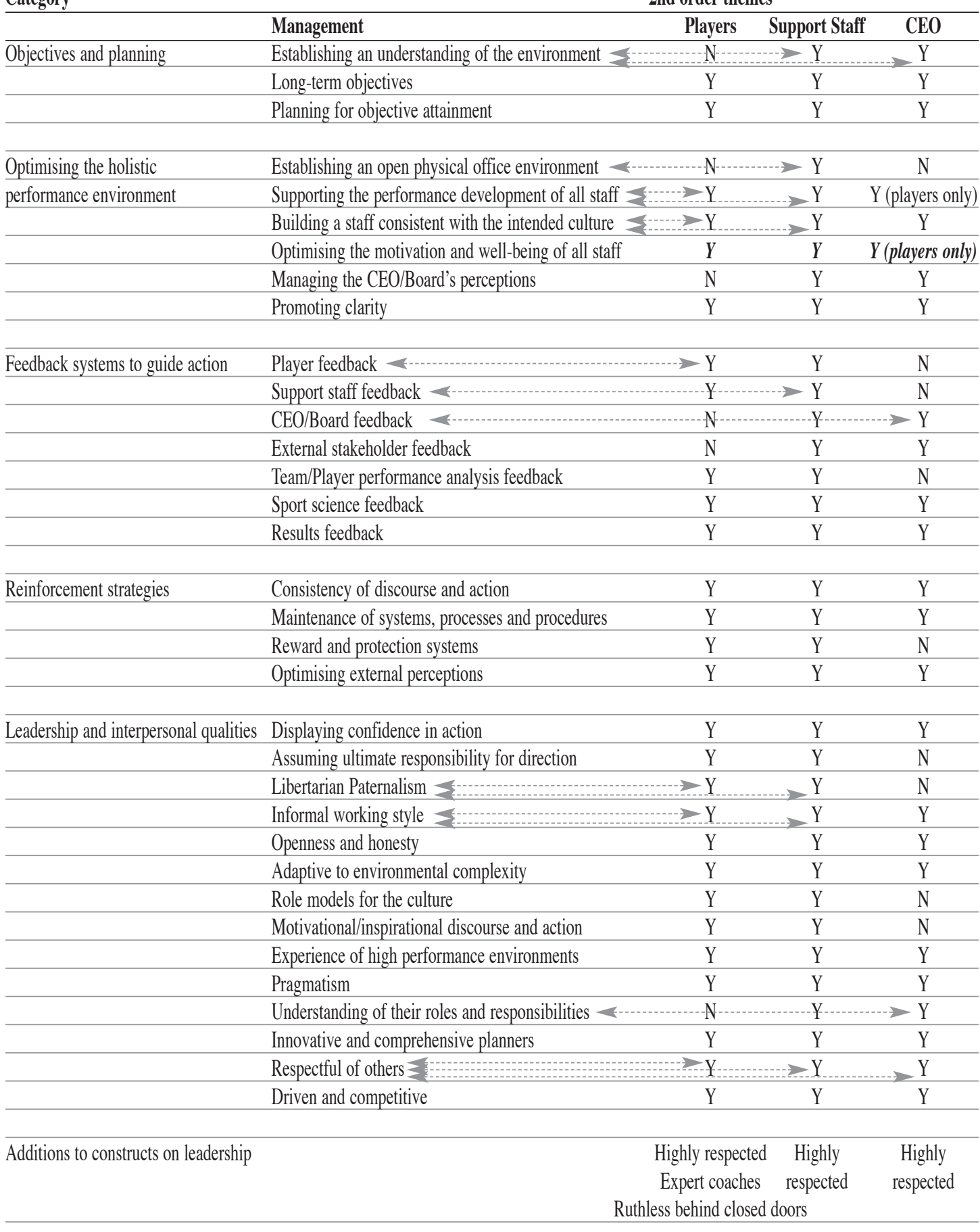

Note. Y's in bold and italic font = themes perceived as having been delivered with sub-optimal efficacy.

--> denote sources which promoted a 'regulated' share of power between management and other group 
of agreement between management and key stakeholders on the methods, phases, and key events of the change programme.

Almost all methods detailed in Table 1 were perceived as effective, with the consistency and maintenance of action, providing ownership, and promoting clarity appearing to have the greatest impact on programme success. For example, the latter theme was manifest across all higher order concepts and included providing all individuals with an understanding of their roles, expectations of their conduct, and the reasons behind the management's past, present, and future action. However, while pan-stakeholder coherence supports the prevalence of a high performing culture, we also briefly consider the limited discrepancies to highlight some key 'decentred' challenges and refine the context against which the culture-facilitating mechanisms and power-sensitive processes can be evaluated.

\section{DISCREPANCIES IN PERCEIVED PERFORMANCE.}

Contrasting the management's view that "where we were going and where our team is going, you have only got to see that the performance got better and better and better" (AK), the other groups commonly revealed that this was not strictly the case (as shown in Figure 1); particularly during the second season when losing eight of the first ten Premiership matches: "It just kind of clicked after a while .... We started off pretty slow and I don't think we kind of gradually got better; we were pretty bad, then slowly we figured it out" (Player 4). As suggested, match outcomes had a greater impact on perceived progress than reported by AK and NB. Contextually significant victories or peak performances, for example after a run of poor results, had the ability to act as tipping points which reaffirmed belief in the programme, created a sense of momentum, and reduced anxiety. While enhanced performance was uniformly perceived across all stakeholders, the challenge of delivering a process-focused culture change in the outcome-focused environment of elite sport was therefore clear.

\section{DISCREPANCIES IN PERCEIVED ACTION.}

Although many themes derived from the CEO were common to other groups (see Table 1), this individual's account was notably not as detailed. This accurate but partially incomplete picture is unsurprising, however, when considering the CEO's lower level of daily interdependence and proximity with other groups. Indeed, the CEO saw such distance as a key feature of his role delimitation against the more 'hands on' managers.

My role is to try and create the perfect rugby environment whereby the coaches can coach and the players can play and there is no external influence at all. I think it's exceptionally important because . . . external influences can be counterproductive and thereby they have no place in the preparation of the squad and its performance.

Against the widespread commonality displayed in Table 1, all groups reported an awareness of some players' disappointment at a lack of information on their exclusion from match day squads; problematic in that inaccurate conclusions were often drawn which then shaped the perceptions of fellow players and staff. This finding again reinforces the decentred nature of elite team culture change and concomitant challenge of creating and sustaining shared and robust performance-optimising beliefs when performers are publicly judged by (non-)selection on a weekly basis. Conversely, however, a number of players did suggest that dissatisfied players were in fact largely responsible for this situation:

Every player thinks he should be playing .... Their door was always open ... and 
they were always honest.... It's quite hard for them to go and see thirty blokes ... and tell them why they're not in the team so players should take responsibility. The guys who were negative were usually the guys not going to see them. (Player 3)

\section{MECHANISMS OF EFFECTIVE CHANGE: THE ROLE OF ENVIRONMENTAL CONTEXTS}

Recognising that the preceding results support the occurrence of effective change, a shift from methods to mechanisms is necessary to address the study's first objective and consider how AK and NB facilitated group acceptance, internalisation, and governance of high performing processes [cf., 2]. Reflecting decentred theory's emphasis on "the need to look for the origins of change in people's contingent responses to dilemmas" [24, p. 8], we specifically focus on how AK and NB facilitated pan-individual uptake of new and more demanding performance-optimising behaviours. Adopting this decentred outlook, programme success was significantly aided by a conscious yet subtle shaping of the context in which stakeholders' decisions were made. Expressly, via subtle regulation of physical, structural, and psychosocial contexts, circumstances were created whereby stakeholders would: a) make their own choices regarding the uptake of performance-optimising or -impairing behaviour, but b) be more likely to consistently make choices which reflected the former and ultimately support enduring optimal performance.

\section{SHAPING THE PHYSICAL ENVIRONMENT}

Of first consideration, reconstructing physical properties emerged as a tactful mechanism for optimising the motivation, performance, and wellbeing of all staff. For example, an openplan environment was installed at the on-site training complex to facilitate the amalgamation and transfer of information and to reinforce the support staff's conceptualisation as a team in its own right.

You could just pull on people all the time for information; you didn't have to get up and go and see if they were in a meeting and knock on the door. So there is just a real ease of access to information and it just keeps people conversing ... swapping ideas, seeing how you can integrate your jobs. Like I used to sit opposite [colleague] and he would say "oh they need to have conditioning here this week is there anything you need to drive home?" . . . between us we would discuss how we can do a practice that will give us a skill and a conditioning element.

(Specialist Coach)

Regarding the separate player environment, during the period of highly demanding physical training constituting pre-season, novel and varied off-site activities were used (e.g., boxing, judo) to maintain optimal application (coincidently, and highlighting how shaping environments could impact upon a number of areas simultaneously, such new activities also acted as a leveller across skill levels, enabling an emphasis on work ethic which was then employed to model behaviour). In similar vein, performance data were also put on public display:

I had a board up there where ... I'd put their tackle completion up, so it was all there black and white for everyone to see and that really generated a lot of interest .... I've heard a lot of blokes coming in and saying "oh I'm only just one tackle off, I don't want to miss any this week I'll remember that." (Specialist Coach) 


\section{SHAPING THE STRUCTURAL ENVIRONMENT Optimising the Structure of the Playing Staff}

Alongside AK and NB's key principle of staff ownership, by creating a squad in which there was competition for every position players' decision making was further shaped to match that required of a high performance athlete. The shift from a culture where players would often drink heavily after away matches represented one clear example of this strategy:

[Player] would come down [the bus] and say "were [sic] we allowed to have a few drinks?" And [NB] would say "well do you think it's the right thing to do?" You put the emphasis back on them .... "Do you think we have earned it today? Is it going to help us if we all get pissed now?" And they would come back and say "no, we can't drink!" ... . There are . . two good players competing for every position .... so there are a lot of pressures on the players to make sure they are in peak physical condition .... they understood they were in a position where they could [drink] but they wouldn't get away with it. (Specialist Coach)

In short, building a squad in which playing ability was evenly balanced in all positions meant that keeping a place in the side required consistent self-adherence to performance-optimising perception and behaviour.

\section{Objective Performance Monitoring and Evaluation}

Extensive monitoring and evaluation of player performance also emerged as a key mechanism for subtly ensuring the continued prevalence of performance-optimising perceptions and practices. For instance, while some players detested training with heart rate monitors in every pre-season session, this condition was recognised as a "small way of getting the best out of people because they won't slack off [as] they can tell how hard you are working" (Player 2). During the competitive season, technical and tactical proficiency was governed by analysis of match statistics against individual and team KPIs. Deployed as part of a pragmatic and evidence-based approach to performance development, its worth in protecting against potential player detraction appeared highly valuable:

They will show us the last game: "Look boys you hit eighty-five [percent tackle success rate] there, this week you hit eighty-eight and you just lost; next week if we hit ninety we'll be there" ... . And then you can break that down individually .... if you can give positive information in that sort of way it's easier for boys to digest and jump on board with the message that we are going in the right direction.

(Player 2)

\section{SHAPING THE PSYCHOSOCIAL ENVIRONMENT Regulated Ownership}

Regarding the psychosocial environment, of initial importance is the recognition that ownership provision was not an unregulated practice. For example, while match preview and review processes sought to encourage player autonomy through extensive questioning and challenging, both management and support staff ensured that answers drawn were those perceived as appropriate and advantageous for optimising performance.

The players decide. We influence them: we talk to them about what are the key aspects in games ... the anatomy of games and things that we want to focus on in 
training. And the players generally, if you have got a rough idea of what you want to do, you sort of work the players around so they give you what you want really. But to be fair they are pretty shared opinions ... what they would be saying would be pretty much in line with what we were thinking anyway. (Specialist Coach)

\section{Leaders, Role Models, and Cultural Architects}

By recruiting players with experience of high-performance environments and whose style of rugby and personality displayed a fit with the management's intentions, change was also largely socially driven through the influence of player leaders, role models, and "cultural architects" [39]. Specifically, beyond peer coaching and expert demonstration, these players' social power was harnessed to optimise group-level acceptance and ownership of processes, systems, and strategies considered necessary to enhance performance. For instance, in a pre-season forum where performance goals and aspirations were obtained, AK reported that "we were smart in a sense of mixing up ... groups, making sure that the balance of the groups, come the end of the forum, would have leaders who would be best suited to summarise the outcomes of the five or six discussed subjects". In this way, selecting and structuring groups around senior players with an expertise in the topic under consideration facilitated the development of a shared and accepted message.

\section{Optimising the Motivation, Wellbeing, and Performance of Non-Selected Players}

Another notable identified mechanism was the provision of extensive support to players periodically, or regularly, not selected in the squad for Premiership matches. Aimed at optimising the holistic training environment by maintaining these individuals' belief in engaging with performance-elevating behaviours, this was achieved by: placing immediate emphasis on these players after a squad was announced; providing an understanding of the reasoning behind non-selection; creating tailored individual development programmes; ensuring playing time in other competitions; and consistent recognition of their contribution, both internally and externally through the media. This finding notably contrasts the earlier perceptions of some aggrieved players, and reflects what was available when players 'bought into' the management's processes and stance.

[Player] ... got put in the team in place of me ... and even through this situation ... it was explained nearly every couple of weeks, informally and formally, of why I wasn't in the team . . . . I haven't been managed like that before . . . It makes me want to train hard, it helps me; I go to sleep at night thinking [NB]'s still supportive of me, he still thinks that I'm part of this group and I'm integral to it. (Player 4)

\section{Promoting Positive Experience with the Wider Psychosocial Environment}

A further mechanism illuminated in promoting a culture of professionalism was the optimisation of players' holistic life experience. For example, visits to local hospitals, young offenders' prisons, and coal pits were arranged to 'ground' the players and promote reflection on the choices they made in the performance environment. Players' time away from the Club was also optimised wherever possible for the same purposes, reflecting a management agenda to ensure regular refreshment and regeneration of the players:

I knew that they were giving them a lot of time off when they can .... [The players] say it just created that unity because all of a sudden the coaches are not just thinking 
of winning all the time, they are thinking of the players being at home and outside rugby and keeping their wives happy and stuff which is important. I suppose you want your wife to be happy for you to be happy, and for the boys that are married and for the boys that are not just to get away and refresh really. (Player 6)

Management of the media's influence on key stakeholders' perceptions was another notable strategy. With such coverage influencing all Club employees, their families and friends, the fans, and the local community, AK and NB provided a consistently positive, future-oriented account of team performances and affairs to minimise the chances of any negative portrayals derailing the culture change programme.

Regardless of whether you have got issues in the camp, you have got to try and portray [a positive image] to the media. I know it's not the be all and end all but guys do read the papers and your mates ring up from other clubs and say "what's going on here?" I do it to other guys if a drama's going on ... . I think it sends a message to our opponents and . . . us the players: You can say something at a meeting which might not hit home but if you hear it in the Press or you see it live in an interview after a game, I think that message carries a bit more weight.

(Player 2)

\section{Managing the CEO's Perceptions}

A final feature in creating a psychosocial environment consistent with the intended culture was management of the CEO's perceptions. For example, as the CEO held "complete control and responsibility" (AK), such action was necessary to retain and not replace certain members of the playing staff and promote enduring, cultural change.

We went through our playing roster [at the end of season 2008-2009] and I said to them "in your opinion is this a genuine Premiership player?" And in the main their perception of the players was higher than mine; but they did point out that to get better quality players would be difficult so in a sense you are better going into the Premiership with the players that we know even though ultimately they are not good enough . . . . I think maybe they felt that they had made a lot of progress in terms of their players' understanding and accepting their way of playing and values. (CEO)

\section{MANAGING AND EXPLOITING THE POWER FLUX}

As suggested by the themes, mechanisms, and quotations presented thus far, appreciation of the power flux which characterises professional sport performance teams appears to have been pivotal in shaping the manner in which change was delivered (see the 'to and fro' interactions detailed in Table 1). For example, AK and NB clearly took steps to minimise the likelihood of potentially dangerous swings in control and, importantly, optimise an ebb and flow of command. Regarding the former, ownership, clarity, enhancing perceptions of and through the media, managing the CEO's views, the influence of leaders, role models, and cultural architects, and objective monitoring and evaluation could all, arguably, be seen as means which protected against potential derailment. Recalling that a to-ing and fro-ing of action should characterise professional sport performance teams, however, more interesting at this juncture are the systems, processes and procedures employed to enable this process.

Inherent within the feedback systems to guide action theme (see Table 1) were a number 
of approaches promoting a transient power share. For example, as well as the previously identified group forums, opportunities for known and anonymous feedback at end of season review meetings were afforded. An intermediary senior players group also appeared particularly valuable and offers a good example of the to and fro interactions highlighted by the decentred approach (see the linking lines on Table 1):

I set up a senior players' group .... . and I had a meeting with my guys once every two weeks and that's when we made our decisions . . . I said to them [senior players' group] "ok what's the issues you want [discussed]" and they gave me all the issues from the players' side, from warm up to everything and I went to [NB] and $[\mathrm{AK}]$ and said "listen I'm just the messenger and these are the issues"... . As players we got across a lot and they gave us a lot that we wanted, like ... warm up [structure] and times of training. So they gave, and I think they wanted things from us and we gave, so I think it was a good give and take relationship. (Player 3)

As an effective adjunct to the senior players' group, the management's "open door" policy and informal working style also promoted similar feedback on a less formal, 'as and when' basis:

For the most part if there's ever any concerns you can just tell them right away, it doesn't have to be a specific time of year or at a meeting when a concern gets raised ... . You can go and you can talk to them and just be like "listen I need you to tell whoever, sort this out, we need to do this, we need to do that", and then they'll just go and talk to the coaches and stuff. (Player 1)

Finally, and significantly, beyond finding a "happy medium" (Player 4) between management and players' wants, the opportunity for such feedback also subtly optimised the governance of performance-facilitating principles by the playing staff; further emphasising how the mechanisms of change operated on a number of levels simultaneously:

At the end of the day the players are out there and the coaches are there to point you in the right direction and if it's the other way round the players won't buy into it, regardless of whether it is about the way they play or the way the place is run. It builds a culture, it builds a team, because everyone becomes tight-knit because we all agree how things should be done .... I hate to keep using that word subconscious, but it is something that only in hindsight when you ask these questions that you think "shit, that's why that was happening. (Player 4)

\section{DISCUSSION}

The present study examined culture change in a professional sport performance department and explained its delivery from a decentred perspective [24]. Regarding the general findings, while elements of establishing an understanding of the environment, long term objectives, and planning for objective attainment emerged as logical starting points, the examined programme did not represent strict, linear steps but instead an integrated, holistic, and dynamic process. In this respect, accordance is found with decentred theory's assertion that social constructions (in our case high performing cultures) are a "complex and continuous process of interpretation, conflict and activity that produces ever-changing patterns of rule" $[24$, p. 7]. This result also aligns with prior sport-specific knowledge in that it is the manner 
in which performance-optimising processes are packaged and deployed which acts as the catalyst for efficient culture change, not strictly the processes themselves [8]. Significantly extending this insight, the current work also revealed that the high-performing culture at Leeds Carnegie was constructed endogenously rather than imposed top-down, with changes consciously engineered through the careful facilitation of stakeholders' actions and beliefs. Additionally, the dynamic, power-governed interactions suggested by decentred theory were apparent and supported as effective by the participants.

Beyond these principle findings, key messages also emerge in relation to the paper's explicit objectives. Firstly, the value of assessing multiple stakeholders' perspectives is evident. Extending upon previous work [7, 8], such enquiry: a) enhanced the completeness of management action, b) promoted an effective verification of this action and its impact, and c) illuminated the socially complex and dynamic nature of professional sport performance team culture change. Shown by the contribution from players, specialist coach, and CEO to the richness of the present findings, these results reinforce suggestions that the optimal development of elite team culture change knowledge may be best supported by research which employs multi-stakeholder designs [2].

Extending upon initial culture change guidelines for sport psychologists working with Olympic sport performance directors [1, 13], the present research offers important implications for the modus operandi of practitioners supporting professional team managers. Beyond support for a number of processes' utility in professional teams (e.g., 360-degree feedback, role clarity, ownership) the most fascinating practical implication centres upon optimising individual and group decision making through subtly shaping environmental contexts. Recognising the anxiety-elevating nature of change, the prevalence of multiple and varied motivations in professional team settings, and the power flux between team management and their staff, players, and superiors, the route to prolonged success may therefore be best achieved by creating contexts which promote, but do not enforce, the consistent uptake of performance-optimising behaviour. By its nature, this result resonates strongly with behavioural economists Thaler and Sunstein [40] and their concept of libertarian paternalism; whereby individuals are free to make choices but guided toward those which lead to optimal functioning (e.g., opt-out instead of opt-in employee savings plans). Aligning with decentred theory's assertion that networks (e.g., performance departments) continually construct, proliferate, and reconstruct their own traditions (i.e., ways of perceiving and behaving), the value of such engineering lies in its ability to facilitate enduring high performance via covertly shaping 'group'-generated and -governed beliefs, expectations and practices; not overt, top-down or transformational direction.

Reflecting the dearth of culture change research in sport psychology and lack of robust theoretical accounts within other disciplines [6], the article also provides initial support for decentred theory as a valuable approach to study in professional sport performance teams. By promoting domain-specific understanding via multiple stakeholder perspectives, the theory's methodological value is evident. Analytically, through an emphasis on individual and social construction, the utility of a decentred approach in accounting for the complex and context-dependent nature of culture change is also apparent through the richness of the results. Finally, by considering power as a construct that flows between actors and groups in all directions, the theory's worth in elucidating systems, processes, and procedures promoting the regulated ebb and flow of control is also clear.

While the study provides a number of bespoke implications for theory and practice, it is important to recognise the study's constraints. Beyond generalisability issues, data veracity may have been restricted by interactional effects such as poor recall, hindsight bias, and self- 
preservation bias [41]. Certainly, deciding to name the club, management, and CEO provides one such source (however, see following paragraph). Due to its retrospective nature, not tracking the evolution of culture in real time also poses concerns over the accuracy of the perceived programme and the precise ebb and flow of power. Finally, the omission of additional key external stakeholders (e.g., the media) and exclusion of performance data analysis represent other notable shortcomings.

Nevertheless, while points for reflection, we encourage the reader to consider an array of characterising traits which support interpretative rigor [cf., 42]. Beyond techniques to address trustworthiness, decentred theory's emphasis on inductive then recentred analyses aligns with study's context and purposes and, of equal importance, social constructionism's major tenets (i.e., consensus of multiple realities) [27, 28]. By interviewing multiple stakeholders with varied roles, responsibilities, and relationships and including all voices in the results, a number of pertinent perceptions are also comparatively represented. Diverging from previous enquiry [e.g., 8], this approach was enhanced by recruiting players who had been: a) exposed to the programme for varying lengths of time, and b) regular and irregular starters in the team (protecting against results as a function of selection). With all players and the specialist coach unconcerned about confidentiality, the likelihood of accurate interpretation was further optimised. Regarding the veracity of data provided by AK, NB and CEO, all three conveyed no concern about being named in the research. Supporting our own belief in the accuracy of these individuals' perceptions, we note that impression management is a mediating factor even in anonymous research and that the CEO's perception of team performance level (cf., Figure 1) does not portray programme success to the same extent as AK and NB, the specialist coach, and players. Additionally, the emergence of the same five higher order themes across all groups (including those whose anonymity has been protected) must be acknowledged.

\section{CONCLUSION}

The study and practice of culture change in professional sport performance teams is a highly complex challenge. The present results also suggest that successful delivery may be best supported by: a) subtly and covertly shaping the physical, structural, and psychosocial context in which support staff and players make performance-impacting choices, and b) regulating the 'to and fro' of social power. Due to its infancy in the sport psychology literature, however, it is vital that future research seeks to extend these initial findings by examining other successful and unsuccessful programmes of change, the differing roles of stakeholders, and the extent of decentred theory's worth as a viable approach to enhancement.

\section{REFERENCES}

1. Fletcher, D. and Arnold, R., A Qualitative Study of Performance Leadership and Management in Elite Sport, Journal of Applied Sport Psychology, 2011, 23, 223-242.

2. Cruickshank, A. and Collins, D., Culture Change in Elite Sport Performance Teams: Examining and Advancing Effectiveness in the New Era, Journal of Applied Sport Psychology, 2012, 24, 338-355.

3. League Managers Association, LMA End of Season Statistics 2010, Retrieved from http://www.leaguemanagers.com/news/news-6585.html

4. Zinser, L., One Loss Away from Unemployment, The New York Times, 2008, Retrieved from http://www.nytimes.com/2008/12/18/sports/18coaches.html

5. Mielke, D., Coaching Experience, Playing Experience and Coaching Tenure, International Journal of Sports Science and Coaching, 2007, 2, 105-108. 
6. Cruickshank, A. and Collins, D., Change Management: The Case of the Elite Sport Performance Team, Journal of Change Management, 2012, 12, 209-229.

7. Lee, S., Shaw, D.J. and Chesterfield, G., Reflections from a World Champion: An Interview with Sir Clive Woodward, Director of Olympic Performance, the British Olympic Association, Reflective Practice, 2009, 10, 295-310.

8. Schroeder, P.J., Changing Team Culture: The Perspectives of Ten Successful Head Coaches, Journal of Sport Behavior, 2010, 32(4), 63-88.

9. Sénecal, J., Loughead, T.M. and Bloom, G.A., A Season-Long Team-Building Intervention: Examining the Effect of Team Goal Setting on Cohesion, Journal of Sport \& Exercise Psychology, 2008, 30, 186-199.

10. Bray, S.R., Beauchamp, M.R., Eys, M.A. and Carron, A.V., Does the Need for Role Clarity Moderate the Relationship between Role Ambiguity and Athlete Satisfaction?, Journal of Applied Sport Psychology, 2005, $17,306-318$

11. Romand, P. and Pantaléon, N., A Qualitative Study of Rugby Coaches' Opinions about the Display of Moral Character, The Sport Psychologist, 2007, 21, 58-77.

12. Callow, N., Smith, M.J., Hardy, L., Arthur, C.A. and Hardy, J., Measurement of Transformational Leadership and its Relationship with Team Cohesion and Performance Level, Journal of Applied Sport Psychology, 2009, 21, 395-412.

13. Collins, D. and Cruickshank, A., "Multidirectional Management": Exploring the Challenges of Performance in the World Class Programme Environment, Reflective Practice, 2012, 13, 455-469.

14. Fletcher, D. and Wagstaff, C.R.D., Organizational Psychology in Elite Sport: Its Emergence, Application and Future, Psychology of Sport and Exercise, 2009, 10, 427-434.

15. Wagstaff, C.R.D., Fletcher, D. and Hanton, S., Positive Organizational Psychology in Sport, International Review of Sport and Exercise Psychology, 2011, Advance Online Publication.

16. Wagstaff, C., Fletcher, D. and Hanton, S., Positive Organizational Psychology in Sport: An Ethnography of Organizational Functioning in a National Sport Organization, Journal of Applied Sport Psychology, 2012, 24, 26-47.

17. Wagstaff, C.R.D., Fletcher, D. and Hanton, S., Exploring Emotion Abilities and Regulation Strategies in Sport Organizations, Sport, Exercise, and Performance Psychology, 2012, Advance Online Publication.

18. Gilmore, S. and Gilson, C., Finding Form: Elite Sports and the Business of Change, Journal of Organizational Change Management, 2007, 20, 409-428.

19. Williams, R,. Euro 2012: Roy Hodgson's Clear Purpose Restores England's Spirit, Retrieved from http://www.guardian.co.uk/football/blog/2012/jun/22/euro-2012-roy-hodgson-england, July $11^{\text {th }} 2012$.

20. Schein, E.H., Organizational Culture and Leadership, Jossey-Bass, San Francisco, 2004.

21. Grix, J., The 'Governance Debate' and the Study of Sport Policy, International Journal of Sport Policy, 2010, 2, 159-171.

22. Goodwin, M. and Grix, J., Bringing Structures Back In: The 'Governance Narrative', the 'Decentred Approach' and 'Asymmetrical Network Governance' in the Education and Sport Policy Communities, Public Administration, 2011, 89, 537-556.

23. Lindsey, I. and Grattan, A., An 'International Movement'? Decentring Sport-For-Development within Zambian Communities, International Journal of Sport Policy and Politics, 2012, 4, 91-110.

24. Bevir, M. and Richards, D., Decentring Policy Networks: A Theoretical Agenda, Public Administration, 2009, 87, 3-14.

25. Bevir, M., A Decentred Theory of Governance, in: Bang, H., ed., Governance as Social and Political Communication, Manchester University Press, Manchester, 2003, 200-222.

26. Potrac, P. and Jones, R., Power, Conflict, and Cooperation: Toward a Micropolitics of Coaching, Quest, 2009, 61, 223-236.

27. Krane, V. and Baird, S.M., Using Ethnography in Applied Sport Psychology, Journal of Applied Sport Psychology, 2005, 17, 87-107. 
28. Gemignani, M. and Peña, E., Postmodern Conceptualizations of Culture in Social Constructionism and Cultural Studies, Journal of Theoretical and Philosophical Psychology, 2007, 27, 276-300.

29. Durose, C., Front Line Workers and 'Local Knowledge': Neighbourhood Stories in Contemporary UK Local Governance, Public Administration, 2009, 87, 35-49.

30. Strean, W.B., Possibilities for Qualitative Research in Sport Psychology, The Sport Psychologist, 1998, 12, 333-345.

31. Stake, R.E., Case Studies, in: Denzin, N.K. and Lincoln Y.S., eds., Strategies of Qualitative Enquiry, Sage, Thousand Oaks, CA, 2008, 119-150.

32. Patton, M.Q., Qualitative Research \& Evaluation Measures, Sage, London, 2002.

33. Ollis, S., MacPherson, A. and Collins, D., Expertise and Talent Development in Rugby Refereeing: An Ethnographic Enquiry, Journal of Sport Sciences, 2006, 24, 309-322.

34. Davies, J.S., The Limits of Joined-Up Government: Towards a Political Analysis, Public Administration, 2009, 87, 80-96.

35. Côté, J., Salmela, J.H., Baria, A. and Russell, S.J., Organizing and Interpreting Unstructured Qualitative Data, The Sport Psychologist, 1993, 7, 127-137.

36. Davis, N.W. and Meyer, B.B., Qualitative Data Analysis: A Procedural Comparison, Journal of Applied Sport Psychology, 2009, 21, 116-124.

37. Faulkner, G. and Sparkes, A., Exercise as Therapy for Schizophrenia: An Ethnographic Study, Journal of Sport \& Exercise Psychology, 1999, 21, 52-69.

38. Bevir, M. and Richards, D., Decentring Policy Networks: Lessons and Prospects, Public Administration, 2009, 87, 132-141.

39. Railo, W., Willing to Win, Amas, Utrecht, 1986.

40. Thaler, R.H. and Sunstein, C., Libertarian Paternalism, The American Economic Review, 2003, 93(2), 175179.

41. Nestler, S., Blank, H. and von Collani, G., Hindsight Bias and Causal Attribution, Social Psychology, 2008, $39,182-188$

42. Sparkes, A. and Smith, B., Judging the Quality of Qualitative Inquiry: Criteriology and Relativism in Action, Psychology of Sport and Exercise, 2009, 10, 491-497. 
Copyright of International Journal of Sports Science \& Coaching is the property of MultiScience Publishing Co Ltd and its content may not be copied or emailed to multiple sites or posted to a listserv without the copyright holder's express written permission. However, users may print, download, or email articles for individual use. 